\title{
Apuntes para el estudio de la religión maya de finales del siglo
}

Caroline Cunill

\section{(2) OpenEdition}

Journals

Edición electrónica

URL: https://journals.openedition.org/jsa/11518

DOI: 10.4000/jsa. 11518

ISSN: 1957-7842

Editor

Société des américanistes

Edición impresa

Fecha de publicación: 5 diciembre 2010

Paginación: 75-100

ISSN: 0037-9174

\section{Referencia electrónica}

Caroline Cunill, «Apuntes para el estudio de la religión maya de finales del siglo xvI», Journal de la

Société des américanistes [En línea], 96-2 | 2010, Publicado el 10 diciembre 2014, consultado el 03 septiembre 2022. URL: http://journals.openedition.org/jsa/11518; DOI: https://doi.org/10.4000/jsa. 11518

All rights reserved 


\title{
APUNTES PARA EL ESTUDIO DE LA RELIGIÓN MAYA DE FINALES DEL SIGLO XVI
}

\author{
Caroline CUNILL *
}

La participación de testigos y escribanos indígenas en la elaboración de los procesos de idolatría contenidos en las probanzas de méritos de los religiosos del Yucatán de finales del siglo xvi favoreció la transcripción de gran cantidad de vocablos en lengua autóctona en las declaraciones. Consideramos que esta característica proporciona validez a este tipo de fuentes para conocer el contenido y el significado de las prácticas religiosas mayas coloniales, así como los mecanismos por los que se transmitieron los ritos prehispánicos en la nueva sociedad, a pesar de las condiciones adversas a su reproducción. [Palabras claves: procesos de idolatría, religión maya colonial, transmisión de conocimientos.]

Notes pour l'étude de la religion maya de la fin du xví siècle. La participation de témoins et de greffiers indiens dans l'élaboration des procès d'idolâtrie du $\mathrm{XvI}^{\mathrm{e}}$ siècle, contenus dans les relations de mérites du clergé yucatèque, favorisa la transcription d'une grande quantité de mots en langue autochtone dans les dépositions. Nous considérons que cette caractéristique apporte une légitimité à ce type de sources qui permettent de mieux connaître le contenu et le sens des pratiques religieuses mayas de la période coloniale, ainsi que les mécanismes grâce auxquels les rites préhispaniques réussirent à se transmettre dans la nouvelle société, malgré des conditions adverses à leur reproduction. [Mots-clés: procès d'idolâtrie, religion maya coloniale, transmission des savoirs.]

Notes about the study of Maya religion at the end of the 16th century. Indian witnesses and notaries' participation in the idolatry processes contained in the yucatecan religious' relaciones de méritos of the I6th century favoured the transcription of many words in autochtonous language in the testimonies. We consider that this characteristic brings legitimity to those sources that enlighten our comprehension of Colonial Maya religion's contents and senses, as well as the mecanisms by which prehispanic rites were transmitted in the new society, despite adverse conditions to their reproduction. [Key words: idolatry processes, Colonial Maya religion, knowledge transmission.]

*Université de Toulouse II-Le Mirail, 5 allée Antonio Machado, 31058 Toulouse cedex 9 [cunillcaroline@gmail.com ].

Journal de la Société des Américanistes, 2010, 96-2, pp. 75-100. O Société des Américanistes. 


\section{INTRODUCCIÓN}

Para los mayas del periodo colonial, al igual que para los demás pueblos indígenas de América, la cuestión religiosa iba a plantearse en términos de conflicto, al tener que elegir entre la religión autóctona y la introducida por los conquistadores, ya que para los españoles la adopción del catolicismo significaba el abandono de las antiguas creencias. Por eso, apenas llegadas al Nuevo Mundo las órdenes mendicantes encargadas de la evangelización empezaron a destruir de forma sistemática las manifestaciones del pasado religioso indígena, tanto materiales, como rituales ${ }^{1}$. Sin embargo, para los indios, la resolución de este conflicto no era tan simple, ya que, por una parte, convertirse al cristianismo no conllevaba el abandono completo de sus creencias y, por otra, abandonar el culto de sus antepasados podía percibirse como una traición. Si a eso añadimos la progresiva aculturación religiosa de los jóvenes indígenas formados por religiosos, la sustitución de los caciques prehispánicos por gobernadores elegidos, por lo general por las autoridades coloniales, y la intensificación del control religioso ejercido ya no sólo por las órdenes mendicantes, sino también por el clero secular, entendemos que en el periodo colonial el panorama religioso autóctono era muy complejo ${ }^{2}$.

Refiriéndose a la conquista militar de la península yucateca, Bracamonte y Sosa (2001) habló de " conquista inconclusa », dado que a lo largo del periodo colonial extensas zonas quedaron fuera del control hispano, dando lugar a un proceso de "perpetua reducción ». La misma expresión podría aplicarse al campo religioso, ya que la evangelización de los naturales de Nueva España nunca llegó a considerarse completa, generando varias campañas de lucha en contra de las manifestaciones de la religión autóctona, llamadas "idolatrías » (Ricard 2001, pp. 387-407; Chuchiak 2000). La extirpación de la idolatría fue la otra cara de la evangelización de los habitantes del continente americano. En el centro de México, en fechas tan tempranas como 1536-1540, el Santo Oficio intentó reprimir las manifestaciones de la religión indígena, condenando a varios indígenas considerados idólatras o hechiceros (González Obregón 2002). En su afán por perseguir este delito, el sistema colonial originó la producción de una rica documentación que, aun siendo el producto de una necesidad colonial, no dejaba de describir una realidad autóctona: los procesos de idolatría.

Si bien, por lo general, los historiadores se han centrado esencialmente en la evangelización y su contrario, la idolatría, y han interpretado la religión autóctona como un espacio de resistencia al orden colonial, con un marcado interés por el sincretismo y la supervivencia de elementos religiosos prehispáni$\cos ^{3}$, en este trabajo quisiéramos poner de manifiesto el funcionamiento interno y el significado intrínseco de las prácticas religiosas mayas coloniales mediante el análisis del juicio realizado contra varios mayas del pueblo de Peto en 1598. 
Desde nuestro punto de vista, la identidad maya de los testigos y de los escribanos que participaron en la elaboración de aquellos procesos proporciona una indudable validez a este tipo de fuentes, ya que no sólo describen las ceremonias, sino que también se adentran en la conciencia de los participantes y las motivaciones que los empujaban a mantener su religión ancestral a pesar de los peligros que esto conllevara. Aunque no cabe duda de que el acopio de una información más sistemática, así como el desarrollo de una metodología pluridisciplinar - con aportes de estudios arqueológicos, iconográficos, epigráficos y antropológicos pudieran esclarecer varios de los aspectos abordados, proponemos que a finales del siglo XvI un grupo de especialistas rituales mayas, jerarquizados y unidos por relaciones familiares, llevaban a cabo clandestinamente prácticas religiosas en las que pretendían recuperar el pasado prehispánico con una clara voluntad, asumida en grados distintos por los participantes, de rechazar las aportaciones del colono en este campo.

\section{JUICIOS DE IDOLATRÍA: VOCES MAYAS EN EL DISCURSO HISPANO}

El proceso de idolatría que nos proponemos analizar se encuentra en la probanza de méritos del clérigo Baltasar de Herrera, hijo de un antiguo poblador de Yucatán, Gaspar de Herrera ${ }^{4}$. Después de haber servido seis años como cura en la isla de Cozumel, Baltasar renunció al beneficio y fue a servir el curato de indios naborías y negros de la villa de Valladolid hasta su nombramiento como vicario del partido de Peto, donde seguía ejerciendo cuando redactó su probanza en 1599. Como prueba de su celo cristiano y su eficacia como vicario en la extirpación de la idolatría, decidió sacar una copia del juicio de idolatría que había realizado entre marzo y julio del año anterior en el pueblo de Peto ${ }^{5}$.

Así, pues, el 14 de marzo de 1598, Baltasar de Herrera había iniciado un juicio de idolatría por venir a su noticia que Francisco Pech, "siendo bautizado, idolatraba con ritos y ceremonias en un ídolo de barro " ${ }^{6}$. Y es que los dos alcaldes del pueblo de Calotmul, al encontrar un ídolo en la milpa de Francisco Pech, habían avisado a su cacique, don Melchior Xiu, el cual « fue personalmente a la milpa del dicho Francisco Pech y trajo el ídolo de barro a su pueblo y luego dio noticia al dicho vicario " ${ }^{7}$. Tan sólo unos días después, entre el 24 de marzo y el 6 de abril, el vicario empezó a interrogar a tres vecinos del pueblo de Peto acerca de la cristiandad del acusado y de la posible implicación de otros indigenas, saliendo a la luz un grupo de ocho mayas relacionados con los ritos del sacerdote ${ }^{8}$. El 15 de mayo, habiéndose ausentado Francisco Sánchez de Urbina, el primer notario nombrado, y ante la necesidad de seguir con la investigación, Baltasar de Herrera nombró al maya Fernando Uxul por escribano. Ese mismo día se interrogó a otros dos testigos. 
Una vez concluida esta primera etapa de la investigación, el beneficiado de Peto remitió la causa al obispo de Yucatán, fray Juan Izquierdo, ya que como provisor general de la diócesis era el único habilitado para dar al cura la potestad para seguir con el proceso ${ }^{9}$. Y es que, como es sabido, después de 1571 se excluyó a los indígenas del fuero del Santo Oficio de la Inquisición, pasando a depender de otro organismo, el Provisorato de Indios (Greenleaf 1965; Chuchiak 2000). El primero de junio, el vicario recibió del obispo la esperada «comisión para conocer idolatrías » y, por tanto, la facultad para concluir el juicio ${ }^{10}$. Antes de mandar prender a los acusados, el cura, siempre por medio del notario Fernando Uxul, recogió otros dos testimonios, el del principal Juan Keh y el del gobernador de Peto, don Pedro Camal. Del 7 al 9 de junio confesaron los diez reos y el 11 del mismo mes el beneficiado dictó su sentencia, ejecutada al día siguiente.

Dado que los juicios de idolatría suelen encontrarse en las probanzas de méritos del clero, es necesario comprender el proceso de generación y las características de este tipo de fuentes. No sólo los miembros del clero, sino también los civiles, esencialmente los conquistadores y sus descendientes, elaboraban probanzas de méritos. Pero, al contrario de las segundas, que han sido abundantemente utilizadas por los historiadores y han condicionado nuestra visión de la conquista y la colonización hispanas, las del clero no han suscitado tanto interés y, hasta la fecha, permanecen poco estudiadas ${ }^{11}$. Y es que varios investigadores consideran que la perspectiva adoptada en estos documentos es hispana y, más concretamente, clerical y no indígena. Clendinnen (1982a, 1984) y Tedlock (1993), por ejemplo, advierten que denunciar idolatrías no resultaba ser un hecho desinteresado para el clero, ya que le permitía conseguir promociones dentro la jerarquía eclesiástica $\mathrm{y}$, por otra parte, insisten en el uso de la tortura para recoger los testimonios indígenas.

No obstante, más recientemente Chuchiak (2002, pp. 140, 143) llamó la atención sobre la riqueza de las probanzas del clero e insistió en su valor no sólo " para estudiar la evolución regional de las percepciones coloniales de la idolatría », sino también como " etnografías accidentales en el estudio de las prácticas religiosas mayas yucatecas en la Colonia ». Según él, la generación de estos documentos era sometida a leyes que pretendían controlar la autenticidad de la información declarada. Entre estos mecanismos de control, existía la obligación de hacer una probanza secreta o de oficio para contraponer las declaraciones del pretendiente a los favores reales con otros testimonios. Por otro lado, ha subrayado que en los juicios no sólo comparecían testigos españoles, sino también indígenas y que, además, se consignaban evidencias materiales. En cuanto a la tortura, recuerda que el clero no podía usarla sin el apoyo del brazo secular, muchas veces reacio a dar su permiso. Finalmente, añade que no siempre le convenía al clero referir casos de idolatría, ya que repetidas denuncias podían desembocar en la mudanza del clérigo de su partido o en la división del beneficio (ibid., pp. 142-149) ${ }^{12}$. 
Desde nuestro punto de vista, una de las principales razones que puede justificar el uso de los procesos de idolatrías como fuentes para el estudio de la religión autóctona en la Colonia radica en el hecho de que en estos documentos intervienen no sólo testigos, sino también escribanos mayas. El uso de escribanos mayas parece haber sido relativamente frecuente, de forma que no fue un caso aislado el nombramiento de Fernando Uxul como notario en el juicio llevado a cabo por Baltasar de Herrera ${ }^{13}$. Chuchiak (2002, p. 147) ha advertido que, en muchos casos, los eclesiásticos necesitaban la ayuda de un personal exclusivamente maya, ya que « el juez local que investigaba a menudo era el único español de la región ». En la probanza de méritos del padre Antonio de Arroyo, por ejemplo, el testigo don Diego Chan, gobernador del pueblo de Tzucacab, afirmó que en 1595 «fue llamado por el dicho padre para que lo ayudase en el descubrimiento y castigo de [la idolatría] y así, como hombre ladino y que sabía leer y escribir, lo nombró por notario " ${ }^{14}$. Pasó lo mismo con don Diego Baz, gobernador del pueblo de Tiquibolon, que «como hombre ladino fue notario del dicho padre Antonio de Arroyo » en el proceso de idolatría hecho en el pueblo de Tixmukul ${ }^{15}$.

El análisis lingüístico del juicio de Francisco Pech y otros mayas del pueblo de Peto permite mostrar que el uso de notarios indígenas contribuyó a la riqueza informativa de estos documentos. Varios investigadores, pertenecientes a la corriente de la "nueva filología », ya han insistido en el interés de la lingüística para el estudio de la historia de América y han puesto especial énfasis en las fuentes redactadas en nahuatl o en maya ${ }^{16}$. Pero, si bien se han realizado apasionantes análisis sobre la integración en los textos indígenas de palabras en castellano, poco se ha escrito sobre el fenómeno inverso, es decir sobre la presencia de palabras indigenas en los documentos hispanos ${ }^{17}$. Y es que, si bien se admite de manera generalizada el fenómeno de « colonización » de las culturas indígenas y, por ende, de sus idiomas, por la cultura del conquistador (Gruzinski 1988), la posición contraria, o sea la influencia de la cultura colonizada sobre la del colonizador, aunque reivindicada por algunos, no ha llegado a estudiarse tanto ${ }^{18}$. No obstante, según Nancy Farriss (1994), de acuerdo con una serie de criterios sencillos, en Yucatán «se podría hablar [...] tanto de un proceso de "mayización", como de otro de "hispanización" ". Entre estos criterios, la investigadora menciona el idioma, ya que considera que « el maya, más que una lengua franca, era el primer idioma de todas las personas nacidas en la Colonia, fuera cual fuera su casta $»$ (ibid.) ${ }^{19}$.

Así, el vicario de Peto, Baltasar de Herrera, era bilingüe y en su probanza señaló que su conocimiento de la lengua maya había constituido una de las principales razones por la cual el obispo Gregorio de Montalvo lo ordenó sacerdote. Por consiguiente, es probable que la producción oral del juicio (interrogatorios, testimonios y confesiones) se hiciera en maya. Por otra parte, aunque la redacción de los procesos se realizara en español, el empleo de un escribano 
indígena favoreció la transcripción de numerosos vocablos mayas. De las 43 locuciones en maya yucateco repartidas en los 27 folios del proceso, solamente dos aparecen en las seis declaraciones recogidas por el notario español en los seis primeros folios. El resto de las voces mayas se encuentran en las deposiciones de los cuatro testigos de Peto y en las confesiones de los diez acusados transcritas por el escribano maya, lo que significa que los vocablos mayas son cinco veces más numerosos en los testimonios escritos por Fernando Uxul que en los de Francisco Sánchez.

Los procesos de idolatría llevados a cabo por fray Diego de Landa en la península en 1562 ofrecen la posibilidad de comparar el documento que nos ocupa con otro, donde la situación de recepción de las declaraciones era lígeramente diferente, dado que se utilizó a un intérprete. En la primera serie de procesos, realizados en 1562 en Sotuta, Kanchunup, Mopila, Sahcaba, Yaxcaba, Usil y Tibolón, tanto el notario como el intérprete eran españoles y en las 60 páginas que conforman la transcripción sólo se encuentran dos mayismos (Scholes y Adams $1938, \mathrm{I})^{20}$. El primero, ah kin y su plural castellanizado ah kines, se repite varias veces en cada uno de los testimonios y únicamente aparece con una glosa explicativa al principio del documento, de forma que se puede afirmar que se trataba de una palabra usual para los evangelizadores de la época (ibid., p. 72). En cambio, el segundo, halach winich, sólo aparece una vez y va acompañado de la glosa del notario Juan de Villagómez, "que es en nuestra lengua gran señor », lo que indica que no era de uso tan generalizado (ibid., p. 107). Sin embargo, cuando el notario sigue siendo español, pero el intérprete es maya, la riqueza lexicográfica maya aumenta significativamente, como en el caso de la información recopilada en Homún en septiembre de 1562.

En sus 27 páginas, este documento cuenta con nueve vocablos en maya yucateco, siendo algunos de ellos usados varias veces, y con tres nahuatlismos, lo cual evidencia que son diez veces más numerosos los términos en maya en las declaraciones cuando el intérprete es maya. Los nahuatlismos - copal, pochote y pozol $^{21}$ - parecen haber formado rápidamente parte del léxico del castellano novohispano, y tal vez hasta del maya hablado antes y después de la conquista hispana, dado que ninguna de estas tres voces va acompañada de glosa explicativa ${ }^{22}$. En cuanto a las voces mayas, dos se refieren a cargos políticos, como ah $\mathrm{kul}$ y batab, o religioso, como ah kin, otra a un guiso (el chacmole), y las demás tienen que ver con los rituales de corte prehispánico. Se menciona así el nombre del pedernal con el que se abría el pecho de las víctimas sacrificiales, llamado $u k a b$ $k u$, «que quiere decir en castellano brazo de los dioses », los cajetes en que se ponía el corazón de la víctima o zuhuy lac, « que en nuestra lengua castellana se dice vírgenes ", la resina de kik quemada delante de los ídolos, el nombre que daban a « los muchachos y muchachas para sacrificar que ellos llamaban antiguamente quymchich » y, finalmente, el nombre del árbol cuyas hojas servían para enramar las iglesias, el copo (ibid., pp. 137, 138-139, 141-143, 145, 148, 152) ${ }^{23}$. 
Notamos que, excepto para las voces referidas a cargos político-religiosos y los dos sustantivos que se refieren a la flora yucateca, el notario español siempre tradujo las expresiones en maya, lo que indica que se trataba de expresiones que no eran usuales, pero que se consideraron suficientemente importantes como para integrarlas al discurso en castellano. En efecto, todas se refieren a prácticas de sacrificios humanos, principal cargo en contra de los acusados. Así, la proporción de palabras mayas depende de la configuración notario-intérprete maya/español. Cuando el notario es español, pero el intérprete es maya, el número de expresiones mayas no lexicalizadas es superior a la configuración notario-intérprete españoles, pero esta cifra crece aún más al ser maya el notario. Por otra parte, la selección de las voces mayas depende del tema de la indagación, es decir de la preocupación principal de los investigadores.

Ahora bien, en el proceso de Francisco Pech y otros mayas del pueblo de Peto, la mayoría de las voces mayas no corresponde ya a los ritos de sacrificios humanos, sino a rituales agrícolas y a las deidades invocadas en tales ceremonias. Por otra parte, la investigación ya no se centra solamente en los ah kines, sino también en sus ayudantes y en las diversas funciones que cumplian estos últimos en las prácticas rituales ${ }^{24}$. En efecto, si bien la palabra ah kin es la más empleada (5 referencias), también aparece el ah kulel y su equivalente castellano « munidor » (1 mención), y el ah patom u ollero (3 alusiones). El mismo número de palabras (9) se refiere a las ofrendas a los dioses: boloncocob (1) - árbol cuya hoja se colocaba debajo del ídolo - y chuyul ha (8) - bebida destinada a los dioses. Pero la mayoría de los términos mayas empleados en el proceso se refiere al panteón autóctono, ya que el notario proporciona el nombre de ocho deidades mayas, con un total de 22 referencias: Ix Ahau Caan (4), Kin Popol Tun (4), Kin Colop U Uich Kin (5), Kin Dzapah Tun (4), Kin Chachau Itzamna (1), Kanleox (2), Ah Chac (1) y Tabay (1). Por fin, Fernando Uxul también menciona el nombre maya de las milpas de dos vecinos: kakalche, cuyo propietario era Gaspar Pix, y kakche, de Francisco Tec.

Por otro lado, es de notar que se hace un extenso uso de varios nahuatlismos. El término pozol, que se refiere a la bebida hecha con cacao molido que se sigue preparando hoy en día en Yucatán, se emplea nada menos que 24 veces para aludir al tipo de bebida ofrendada a los dioses tradicionales. La palabra copal (del nahuatl copalli) o incienso blanco usado durante las ceremonias religiosas aparece 10 veces en el proceso, pero no se menciona la voz maya equivalente, pom. De la misma manera que en la Historia de las cosas de Nueva España de Sahagún (2001 [1577]), tanto la voz pozol como copal forman parte de los « términos que alternan entre la explicación y la aparición normalizada en el discurso », lo que indica el grado de generalización de estas palabras venidas del nahuatl y que pasaron al léxico corriente tanto de los mayas como de los españoles (Bastardín Candón 2001, p. 122). Aún más integrado debió de estar el nahuatlismo jicara, utilizado para referirse al tipo de vaso que contenía el pozol, ya que el notario- 
intérprete ni siquiera experimenta la necesidad de explicar este término ni una sola vez ${ }^{25}$. La palabra cuzca, que viene del nahuatl cuzcatl y significa piedra preciosa, es utilizada una sola vez y aparece sin glosa ninguna ${ }^{26}$.

Otra característica de los testimonios recogidos por el notario maya Fernando Uxul, consiste en el recurrente uso del discurso directo, traducido directamente al castellano, para reproducir las declaraciones de los testigos. Esta modalidad enunciativa está presente tanto en las declaraciones, como en las confesiones de 8 de los 17 indígenas interrogados. En total, son 20 réplicas en discurso directo, entre las cuales algunas aparecen como un diálogo entre locutores, mientras que otras son monólogos, como, por ejemplo, las oraciones pronunciadas por el ah kin Francisco Pech durante las ceremonias ${ }^{27}$. Los enunciados reportados implican a una variedad bastante grande de locutores, tanto en situación de desigualdad jerárquica (adulto/niño o alcalde/indio del común), como en situación de igualdad (dos compadres). Los diálogos entre marido y mujer son difíciles de clasificar, aunque pueden entrar en el marco de las relaciones jerárquicas con una tendencia de la mujer - que puede parecer sorprendente, pero que intentaremos interpretar - a dominar en el intercambio.

Por lo general, a los testigos nunca se les atribuyen discursos propios. Sólo el alcalde Francisco Che, al contar su intervención en la confiscación del ídolo a Francisco Pech, se atribuye una réplica, con el claro objetivo de poner de manifiesto su propia eficacia en el asunto. El segundo y último testigo que refiere palabras propias es Juan Tun: en su testimonio, ya no en su confesión, intenta minimizar su participación en los ritos, al consignar un intercambio oral con su difunta mujer, Ana Dzuma. Pero, entre las cuatro réplicas contenidas en su declaración, tres corresponden a su mujer y sólo una a él mismo. Parece, pues, claro que el rechazo del discurso directo tiene que ver con la voluntad, por parte de los procesados, de evitar su propia responsabilidad y, al contrario, acentuar la ajena, lo que se entiende por la situación de denuncia, con el consiguiente temor al castigo al cual estaban expuestos. En efecto, 14 de las 20 réplicas van atribuidas al principal acusado, el sacerdote Francisco Pech, estando la mayoría de ellas (10 de las 14) concentradas en las cuatro confesiones de los inculpados, momento crítico para ellos, ya que de ellas dependía la sentencia. Así, el análisis lexicológico en maya y el discursivo en castellano demuestran lo adecuado que resulta ser este tipo de fuentes para el estudio etnohistórico de las prácticas religiosas mayas del periodo colonial.

\section{DIMENSIONES SOCIAL E IDEOLÓGICA DE LA RELIGIÓN MAYA}

Aunque el proceso de Peto brinda valiosas informaciones acerca de las ceremonias autóctonas de finales del siglo XvI, ilustrando hasta qué punto este tipo de documentos puede enriquecer el conocimiento del panteón, la cosmovi- 
sión y los rituales autóctonos, estos aspectos se describirán brevemente, ya que consideramos que su análisis requiere de estudios multidisciplinarios más profundos, con aportaciones de especialistas de la iconografia, la lingüística y la antropología maya ${ }^{28}$. En el proceso se mencionaron los dioses Kin Popol Tun, Kin Dzapah Tun, Kin Colop U Uich kin, Ix Ahau Caan y Kin Chachau Itzamna. Dos de ellos aparecen en el Ritual de los Bacabes, conjunto de plegarias, conjuros y recetas médicas redactado a finales del siglo xvı en Nunkini. Se trata de Kin Popol Tun, traducido por Ramón Arzápalo como « Día-de-reunión-alrededorde la piedra preciosa », y de Kin Colop U Uich Kin, «El-sol-del-rostrodesollado » (Arzápalo Marín 2007, pp. 15, 34, 44, 45, 47, 50). Al parecer, este dios evoca metafóricamente el mal padecido por los enfermos y que el curandero debe localizar. Kin Dzapah Tun podría traducirse literalmente por « Día-detener-la Piedra », puesto que, según el Calepino de Motul, el término dzapah significa « sumirse, atestarse, atascarse o atollar» (Arzápalo Marín 1995, I, p. 213). Aunque estas deidades parecen haber sido las principales, no eran las únicas, ya que Gaspar Pix y Juan Na poseían un ídolo llamado Kanleox, cuyo nombre Mercedes de la Garza traduce por la « Señora del precioso capullo de hojas » ${ }^{29}$. Por otra parte, Pedro Pix confesó haber idolatrado en Tabay, « dios de la caza y montería » y Ah Chac, " dios de la lluvia », según las glosas del notario Fernando Uxul ${ }^{30}$. También se encuentran alusiones a Tabay en las confesiones de los mayas enjuiciados en Maní en 1562, donde varios inculpados declararon haber of recido copal y sangre de venado a los ídolos " porque le diesen ventura en la caza " y el testigo Juan Tzuc precisó que " aquel diablo se llamaba Tabay » (Scholes y Adams 1938, I, pp. 59, 63) ${ }^{31}$. Al parecer, Kanleox, Tabay y Ah Chac eran adorados en las milpas, seguramente porque estaban asociados con el maíz, la caza y la lluvia, respectivamente ${ }^{32}$.

Según la información del proceso, los mayas solían conservar la mayoría de sus ídolos en milpas y cuevas ${ }^{33}$. Ix Ahau Caan se encontraba en la milpa del sacerdote Francisco Pech, del mismo modo que Kanleox en la de Gaspar Pix. Juan Tec también guardaba en su milpa un ídolo, cuyo nombre no se especificó. En cuanto a Juan Na, había depositado una representación de Kanleox en una cueva. Si bien Pedro Col declaró que Agustín Dzul y Juan Tec escondian a Kin Dzapah Tun, Kin Popol Tun y Kin Colop U Uich Kin, no precisó dónde ${ }^{34}$. Pedro Pix tampoco reveló donde guardaba a Tabay y Ah Chac. Siete de los nueve acusados poseían, por tanto, uno o dos ídolos, lo que sugiere que éstos estaban repartidos entre los participantes, tal vez con el fin de minimizar los riesgos de ser descubiertos y los castigos que las autoridades coloniales reservaban a este delito, ya que el hallazgo de un ídolo se interpretaba como una prueba tangible de la idolatría de su propietario ${ }^{35}$.

Así se pueden explicar las señales de turbación que manifestó Francisco Pech cuando los alcaldes de Calotmul descubrieron el suyo, señales que no les pasaron a éstos desapercibidas, dado que en sus testimonios insistieron en « que luego que 
hallaron el dicho ídolo se lo mostraron al dicho Francisco Pech, el cual se demudó y mostró pesar y que estuvo un rato callado y suspenso ${ }^{36}$. Y es que, además, el ídolo era considerado como una evidencia material de las prácticas idolátricas de los acusados y, en este caso, fue mandado al vicario y, posteriormente, al obispo de Yucatán. Por esta razón, los mayas intentaban proteger el secreto de su localización lo mejor posible, llegando a usar la amenaza para alejar a los curiosos. Así, Francisco Pech habría «amenazado a muchos indios, diciendo les ha de flechar si pasan por la dicha milpa » y habría dicho a un hijo o sobrino suyo: "No lleguéis a ese ídolo, ni lo toquéis, porque el que llega a él muere luego $»{ }^{37}$.

Encontrar restos de ofrendas alrededor de los ídolos constituía una prueba suplementaria de la culpabilidad del dueño, por lo cual las descripciones al respecto suelen ser bastantes precisas. Según el proceso de 1598, en aquella época los mayas ofrendaban a sus ídolos copal, tortillas, venado, cuzcas y hojas de un árbol llamado voloncocob ${ }^{38}$. Aunque esta voz no se encuentra en el Calepino de Motul, se compone del numeral bolon «nueve » y del vocablo kokob, de forma que no sería extraño que este árbol, en cuyas hojas se depositaban los ídolos, estuviera relacionado con el número nueve, asociado con el inframundo en la cosmogonía maya ${ }^{39}$. El proceso también ofrece detalles sobre el chuyul ha, bebida hecha con cacao pozol. En una de sus glosas, Fernando Uxul explicitó que el confesante había dado dos veces « cuatro jicaras de chuyul ha, que en nuestra lengua se interpreta sacrificio ", confirmando la interpretación dada por Juan Tun en su confesión, según la cual « se llamaban estas cuatro jícaras de cacao poçol chuyul ha, que así la llamaban los antiguos idólatras, siendo sacrificio y que era sacrificio que enviaban al cielo ». Otra característica del chuyul ha es que se repartía en cuatro jícaras, las cuales eran « colgadas ». De ahí el comentario de Ana Quime que confesó que los acusados «bebían poçol colgado que llaman chuyul ha » ${ }^{40}$. Ésta parece ser la traducción más literal de la expresión, dado que ha significa " agua " y chuuyul, « ser colgado o estar en el aire colgado » ${ }^{41}$. Tanto el ofrecimiento como el consumo de esta bebida seguía un riguroso ritual: primero, el ah kin se encerraba en un aposento donde daba las ofrendas a los dioses, rogándoles las recibieran y cumplieran con las peticiones de los participantes y, luego, se consumía el contenido de las jicaras, respetando la jerarquía, ya que el neófito solía ser el último en beber ${ }^{42}$.

Y es que el juicio de Peto también contiene interesantes datos sobre la identidad y la organización de los participantes de las mencionadas ceremonias. Según Chuchiak (2001, p. 138), a lo largo de la Colonia se mantuvo una jerarquía entre los sacerdotes mayas, siendo el cargo de Ah kin May o Ahau Caan, guardián de los códices sagrados y responsable de la educación de los demás sacerdotes, el más elevado. Además, cada pueblo solía tener cuatro ah kines, repartidos entre los tradicionales cuatro barrios y ayudados por varios asistentes: los chac, que representaban los cuatro aspectos del dios de la lluvia, los nacomes, 
encargados de realizar los sacrificios, y el ah kulel, responsable de reunir a los miembros para las ceremonias ${ }^{43}$. Ahora bien, en el proceso de 1598 el personaje más prominente fue el ah kin Francisco Pech, " el mayoral y cabeza de ellos » ${ }^{44}$. En términos de justicia eclesiástica, fue condenado "por idólatra y autor de idolatrías y sacerdote ah kin de ellas, por embaidor y engañador de cristianos y porque atrajo a las dichas idolatrías a ocho indios y una india haciéndoles usar ritos y ceremonias antiguas $»{ }^{45}$. Al parecer, era el único ah kin del grupo y era ayudado por el ah kulel Pedro Col, de 20 años. Agustín Dzul fue el testigo que más claramente explicó las funciones de Pedro Col, al asociar la voz maya con la castellana: « el que los munía y llamaba a los dichos ritos era y fue Pedro Col que servía de munidor y ah kulel» ${ }^{46}$. Según Covarrubias (1995, p. 769), el munidor era " el ministro de la cofradía, que va avisando a los cofrades que acudan a los entierros, del nombre latino monitor ». El Calepino de Motul proporciona dos entradas para la voz ah kulel, la primera pertenece al campo civil, ya que se define como " cierto oficial de república menor que los ah cuch cabe y mayor que los tupiles. Idem, abogado, medianero y tercero entre algunos ». La segunda, que se aproxima más al sentido de munidor, dice: « veedor, o como maestresala. Idem, corredor de lonja $\gg{ }^{47}$.

Otro oficio relacionado con los ritos mayas era el de ollero o ah patom. Sin embargo, en el proceso no se estableció ninguna relación explícita entre el maya ah patom y su traducción española. Ana Quime fue la primera en aludir a un enigmático ah patom Chim, sin más explicación. En el siguiente testimonio, Catalina Dzul mencionó que patom Chim era la forma maya de referirse a Andrés Chim, pero no explicitó el significado de este nombre y sólo más adelante la misma testigo, al referirse a este personaje, añadió que era ollero ${ }^{48}$. Todo parece indicar que ah patom Chim era simplemente el nombre maya de Andrés Chim y que tal denominación no tuviera nada que ver con sus actividades de ollero, por lo que, al ser independiente de su nombre maya, el trabajo de ollero se asociara a la esfera hispana y no a la maya. Por otra parte, es de notar que en ningún otro testimonio se volvió a precisar el oficio de Andrés Chim y que tampoco se aludió a ello en su propia confesión, ni en la condena dada por las autoridades, de forma que parece que tanto el propio Chim, como sus compañeros quisieron omitir deliberadamente este dato para que el vicario Baltasar de Herrera no se fijara en ello. Sin embargo, en una comisión dada en 1592 al vicario de Chancenote, el padre Antonio de Arroyo, el provisor, pedía al vicario que encontrara « los que sirvieron de ah kines y los que son maestros de hacer los ídolos y los bendicen y los que sirven de chaques $\gg{ }^{49}$.

De hecho, como lo puso de manifiesto Chuchiak (2009), para los mayas fabricar ídolos de barro era un « oficio religioso », pues en su elaboración se hacían ritos en los cuales era esencial incluir restos de antiguos ídolos en los nuevos. Una confirmación de nuestra hipótesis de que paton o ah paton aludía a la profesión de fabricante de ídolos, la encontramos en los juicios de idolatrías de 
Maní de 1562, donde el testigo Juan Chan confesó tener diez ídolos de barro " hechos a manos de un Poton Cauich, que es ya muerto y murió infiel » (Scholes y Adams 1938, I, p. 60). En este caso, lo que podría parecer como un simple nombre antepuesto al apellido, poton, indica en realidad la función de la persona, aunque las autoridades coloniales no parecen haberse fijado en ello, de la misma manera que, a pesar de la supuesta preparación que tenían los vicarios, Baltasar de Herrera no sospechó de Andrés Chim y, al final, no lo condenó por ollero - lo que hubiera agravado su pena -, sino por idólatra con la misma sentencia que la de los demás acusados del proceso.

$\mathrm{Al}$ contrario de lo que sucedió con Andrés Chim, cabe mencionar el interesante caso de Ana Quime, una mujer maya severamente castigada en el proceso, por considerarse que ocupaba un cargo importante dentro de la jerarquía « idolátrica ». En la sentencia, donde se menciona a los condenados por orden según la gravedad de su culpa, Ana Quime aparece en tercera posición, después del ah kin Francisco Pech y del munidor Pedro Col. Se la condenó a 24 azotes y a que oyera misa desnuda desde la cintura, con una vela encendida en la mano, soga al pescuezo y « coroza » en la cabeza, « porque hizo y preparó los sacrificios que se ofrecieron a cuatro ídolos y por haber comido y bebido de ellos muchas veces $"{ }^{50}$. El hecho de que no sólo consumiera los alimentos que se ofrendaban, sino que también los preparara explica la severidad del castigo, puesto que para los mayas tal actividad era considerada como un verdadero oficio religioso y respetada como tal. Agustín Dzul explicaba que Ana Quime era « la que hace el pozol y cacao de los sacrificios » y que " para el efecto [...] la llaman a casa del dicho Francisco Pech, sacerdote, cuando se ha de hacer los dichos ritos y ceremonias con el dicho pozol y cacao y como tal oficiala la respetan y honran los de la dicha junta ${ }^{51}$.

Esto confirma la observación de fray Diego de Landa según la cual los mayas « eran tan dados a sus idolátricas oraciones, que en tiempo de necesidad hasta las mujeres, muchachas y mozas entendían en esto de quemar incienso y suplicar a Dios les librase del mal y reprimiese al demonio que ello les causaba » (Landa citado por Solís Robleda 1994, p. 6). Según Irene Silverblatt (1990, p. 147), en el Perú del siglo XVII la mujer también fue perseguida « como participante y líder clave en la adoración de los prohibidos cultos indígenas ». De modo que la cuestión de género constituye una categoría válida para entender los mecanismos de implicación de los mayas en las prácticas religiosas ${ }^{52}$. Ana Quime hasta llegó a utilizar el argumento genérico para intentar minorar su castigo, al pedir al vicario que la perdonara porque « como mujer flaca pecó ${ }^{53}$. Es interesante constatar que usó la ideología católica y el tema de la debilidad de la mujer pecadora, tal como debían de enseñarlo los religiosos, demostrando cómo las mujeres mayas eran capaces de utilizar tanto los conocimientos antiguos, como los elementos de la nueva religión para situar y defender su posición en la sociedad colonial ${ }^{54}$. 
El caso de Juan Tun aporta datos sobre el papel de las mujeres en el mantenimiento y la transmisión de las costumbres antiguas. Con el objetivo de minimizar su grado de culpabilidad, este acusado quiso explicar por qué empezó a idolatrar y reprodujo, en discurso directo, una conversación que mantuvo con su difunta mujer, Ana Dzuma. Declaró que su difunta esposa le había preguntado si «ten[ía] noticia de cómo nuestros antepasados hacian que lloviese en sus milpas ». Al responderle que no, agregó la mujer: "Sabrás que se juntaban y comían y bebían y hacían otras cosas y que así tenían buenos temporales y ésto me dijo María Quime, mujer de Andrés Chim » ${ }^{55}$. La versión de Catalina Dzul, la testigo precedente, difiere lígeramente de la de Juan Tun, dado que, según ella, fue el marido quien se puso en contacto con Andrés Chim y que la mujer, Ana Dzuma, sólo contribuyó a convencerlo a que participara en las juntas. Es probable que, por miedo al castigo, Juan Tun intentó minimizar su responsabilidad y que el hecho de que su mujer hubiera muerto pudo influir para que le echara a ella la culpa de su idolatría. Aunque es difícil saber a ciencia cierta lo que se dijeron marido y mujer, las declaraciones de ambos testigos muestran que las mujeres desempeñaron un papel importante en el proceso de reclutamiento de un neófito. La mujer de Juan Tun, Ana Dzuma, lo persuadió a que volviera a celebrar los ritos antiguos, y para ello recurrió a otra mujer, Maria Quime, esposa de Andrés Chim, con el fin de que aprendiera cómo se preparaba el chuyul ha en tiempos prehispánicos.

Así, en el proceso de 1598 nada menos que cuatro de las esposas de los nueve inculpados fueron implicadas, en mayor o menor grado: Ana Quime, la mujer de Juan Na, María Quime, la de Andrés Chim, Ana Dzuma la de Juan Tun y, por fin, la mujer de Agustín Dzul, cuyo nombre no se revela. Catalina Dzul, la nuera del sacerdote Francisco Pech, también ayudó a preparar las ofrendas a los dioses ${ }^{56}$. Sin embargo, fue la única que intentó resistirse y hasta amenazó con denunciar a su suegro, aunque parece que lo hizo más para evitar las molestias de tener que despertarse por la noche « para dar pozol y molerlo » que por reales convicciones religiosas, ya que confió a su hermano: « Si tanto me hace mi suegro y tanto me maltrata, descubriré su negocio y daré de él noticia » ${ }^{57}$. Lo más interesante del caso de Catalina Dzul, y en lo que, sin embargo, el vicario parece no haberse fijado, son sus lazos familiares. En efecto, era la hija de Ana Quime, la citada oficiala condenada a una grave pena, y de Juan $\mathrm{Na}$, uno de los idólatras inculpados. Por otra parte, como se ha mencionado, era la nuera del sacerdote Francisco Pech. Es decir, que las dos familias de idólatras estaban unidas por una alianza matrimonial que, de cierto modo, sellaba su complicidad y su compromiso religioso por los vínculos de parentesco.

Las mujeres también intervinieron en la transmisión de los ídolos dentro de las familias, como se desprende de la confesión de Agustín Dzul. En efecto, este acusado reconoció que los dos ídolos que poseía pertenecían originalmente a su suegro, Francisco Chan quien, al morir, los dejó en herencia a su hijo Francisco 
Cob. Un año antes de que muriese este último, llevó a Agustín Dzul « adónde estaban los dichos ídolos y le hizo ofrecer sacrificio y, por fin y muerte del dicho Francisco Cob, su cuñado, hubo este dicho confesante en herencia y guardia los dichos ídolos " ${ }^{58}$. En este caso, el papel de las mujeres en el traspaso de ídolos fue doble, dado que Francisco Cob estaba casado con una hermana de Agustín Dzul y la mujer de Agustín Dzul era hermana de Francisco Cob. Así, esos matrimonios entre pares de hermanos legitimaron la transmisión de los idolos entre los hombres. Al analizar el papel de « los vínculos sociales en la difusión clandestina de textos rituales » nahuas y zapotecos en la primera mitad del siglo XvII, David Eduardo Távarez (1999, p. 236) también advirtió la existencia de « un interesante eje social por el cual se transmitían textos y conocimientos rituales entre especialistas miembros de la misma generación y de un marido especialista a otro sucesivo dentro del mismo lugar matrilocal ».

En varias ocasiones el sacerdote Francisco Pech expresó el contenido ideológico de sus creencias, relacionado con cuestiones étnicas, ya que la religión constituía una forma de reivindicar la cultura y la organización social prehispánicas ${ }^{59}$. Cuando los alcaldes de Calotmul le preguntaron de quién era el ídolo que tenía en su milpa, replicó que era "de los indios antiguos ». Aunque esta respuesta pudiera interpretarse como una manera de evadir su responsabilidad, como si el ídolo sólo fuera un vestigio inusitado del pasado prehispánico, las insistentes preguntas de los alcaldes hicieron que saliera a la luz el sentido provocador de esta aserción, ya que Francisco Pech agregó: "¿Por qué razón tengo que echar de su casa al que ha mucho tiempo que tiene de ella posesión? ${ }^{60}$. Este argumento ponía explícitamente en tela de juicio la legitimidad de la evangelización, al hacer hincapié en la antigüedad de la cultura y la religión mayas autóctonas. Francisco Pech recurrió a un razonamiento similar con el fin de convencer a Pedro Col a que se juntara con él para practicar las ceremonias antiguas, explicando: « Nuestros padres acudieron a estas cosas y no podemos dejar de acudir a ellas y el que quisiere dejarlas bien puede, pero yo sé el mal que le vendrá $"{ }^{61}$.

La abierta competencia entre la religión autóctona y la católica se plasmó también en el desplazamiento de una imagen de San Juan que tenía Juan Na en su casa, ya que, a petición de Francisco Pech, este maya decidió devolverla a la iglesia del pueblo, convencido por las palabias del sacerdote que le había dicho: "Tienes esta imagen aquí que me da gran temor. Sábete que estás maldito de Dios por tenerla aquí porque no nos pertenece a nosotros sino a los españoles ». En este caso la cuestión religiosa se revestía de una obvia dimensión étnica, la lucha entre íconos religiosos representando metafóricamente la lucha entre españoles e indios ${ }^{62}$. Así, la religión se convirtió en una manzana de la discordia para la sociedad maya de finales del siglo xvi: cristiandad o gentilidad se oponían en cuestiones que iban más allá de lo religioso, al proponer un esquema interpretativo del mundo que cuestionaba el sistema colonial mismo. 
Sin embargo, según los testimonios del proceso, sólo una minoría de los mayas interrogados reivindicaban de manera activa la ideología subversiva de su sacerdote, dado que, por lo general, acudían a las antiguas prácticas por motivaciones de tipo agrícola. En efecto, en su intento por explicar por qué empezó a idolatrar, Juan Tun insistió en que esperaba que, al venerar a sus antiguos dioses, " llovería ordinariamente en su milpa y tendría siempre maíz y no le faltaría de comer ${ }^{63}$. La sequía debió de acelerar su decisión, ya que explicó que era necesario que « lloviese porque había mucha seca y soles muy grandes ». En sus ceremonias, la lluvia y las buenas cosechas eran las dos cosas que solía pedir el sacerdote a las deidades invocadas. Los sacrificios se ofrecían a Kin Popol Tun y Kin Dzapahtun, « los cuales son los que dan vida y lluvia y mantenimiento » ${ }^{64}$. Lo mismo pidió el sacerdote en otra ocasión: "Señores, este sacrificio que ofrecemos y me postro a tus pies y me pongo debajo de tus manos, envíanos aguas y todo lo que nos es necesario $"{ }^{65}$.

Para ellos, la dimensión ideológica se limitaba a un conflicto entre el pasado y el presente entre las tradiciones antiguas y las nuevas costumbres, más que a una lucha en contra del sistema colonial y de los españoles. El caso de Juan Tun es esclarecedor, dado que, cuando su difunta mujer le pidió que formara parte de la junta de los idólatras, le respondió que estos rituales ya formaban parte del pasado irreversible y le dijo: " No trates de estas cosas porque son ya pasadas ». El miedo al castigo también explica las reticencias de los mayas para mirar hacia atrás, como lo demuestra lo que respondió Juan Tun a su mujer cuando intentó persuadirlo: "Sí hiciera, pero es negocio que si se descubre cuesta caro y me vendrá mucho mal e inquietud » ${ }^{66}$. El joven Pedro Quime manifestó la misma convicción de que las ceremonias practicadas por el sacerdote Francisco Pech pertenecían a un pasado que era preferible no volver a invocar, tanto por su lejanía y la ignorancia de la mayoría de los mayas acerca de sus antiguas tradiciones, como por el peso de su educación cristiana y el peligro que entrañaba seguir adorando a los dioses autóctonos. Así, en su confesión explicó que « se apartó de ellos porque no le parecía bien y porque entendió que no habían de parar en bien los que usaban de aquellos ritos y que les había avisado no usasen de aquellas cosas porque no eran buenas ». Sin embargo, Pedro Quime no denunció a sus convecinos, lo que muestra cierto grado de solidaridad pasiva con los mayas inculpados, a pesar de que el discurso colonial y cristiano impregnara tanto su conciencia como su confesión, ya que reconoció « haber errado en no lo haber hecho ». Su arrepentimiento no bastó para que escapara del castigo, aunque su condena fue menor que la de los demás acusados ${ }^{67}$. 


\section{CONSIDERACIONES FINALES}

El proceso de 1598 sugiere, por tanto, que entre los mayas de finales del siglo Xvı la religión autóctona se planteaba más en términos de resurgimiento que de continuidad, ya que adoraban a sus dioses antiguos en función de los conocimientos que habían logrado transmitirse de generación en generación, de los aportes del cristianismo y del nuevo contexto de represión ${ }^{68}$. De esta forma, las prácticas religiosas mayas de corte prehispánico se entendían como una especie de conservadurismo religioso en el seno de la sociedad maya de la época. Por esta razón, interesa analizar tanto la transmisión de conocimientos tradicionales, como el reclutamiento de nuevos miembros. Aunque el objetivo del vicario consistía en delimitar las responsabilidades, personalizar los castigos y buscar a un culpable cuyo castigo fuera ejemplar y aunque, por tanto, la visión colonial tendiera a simplificar los mecanismos que impulsaban a los mayas a idolatrar, una lectura atenta del proceso de Peto permite vislumbrar el papel de los lazos familiares en el mantenimiento y la difusión de la religión autóctona maya, ya que el afán de minimizar las responsabilidades propias llevaban a los testigos a referirse a familiares, principalmente, a la familia política o a los difuntos. En estos mecanismos, las mujeres mayas no fueron víctimas, sino actores que también determinaron el curso de la historia de los pueblos indígenas durante la Colonia.

Por otra parte, la dimensión ideológica, más o menos asumida por cada miembro, reforzaba su adhesión, supliendo las lagunas del pensamiento y del ritual cristiano que se comunicaba a los mayas. Tal situación exacerbó la competencia entre los mayas que pretendieron construir su legitimidad en los fundamentos del sistema colonial y aquellos que, excluidos de él, prefirieron crear medios paralelos en los cuales el pasado y la tradición mayas desempeñaron un papel preponderante. Aunque a pocos años de la Conquista eran numerosos los caciques que seguían practicando ritos de corte prehispánico, en el proceso de Peto varios miembros del cabildo prefirieron colaborar con el vicario para encontrar a los idólatras. Esta actitud era conforme a las expectativas coloniales y a los mandamientos que recibían los gobernadores al ocupar sus cargos, ya que una de sus tareas consistía en vigilar la " policía y cristiandad » de los vecinos, arriesgando sus puestos si no cumplían con esta obligación ${ }^{69}$. Pedro Keh, principal del pueblo, señaló que «siempre que se ofrece los dichos [idólatras] llaman al dicho Francisco Pech almehen », como si el ah kin usurpara indebidamente un título que no le correspondía, lo que muestra la abierta competencia que existía entre los principales y los sacerdotes tradicionales, ya que ambos grupos reivindicaban su legitimidad como gobernantes y aspiraban al control y prestigio de cara a sus convecinos, apoyándose en ideologías opuestas ${ }^{70}$.*

* Manuscrit reçu en novembre 2009, accepté pour publication en juillet 2010. 


\section{APÉNDICES}

\begin{tabular}{|c|c|c|c|c|}
\hline $\mathrm{N}^{0}$ & Vocablo maya & Traducción & Locutores & Folios \\
\hline 8 & chuyul ha & agua colgada & $\begin{array}{l}\text { Juan Tun } \\
\text { Juan Tec (3vcs) } \\
\text { AgustínDzul (2vcs) } \\
\text { Ana Quime } \\
\text { Pedro Quime }\end{array}$ & $\begin{array}{l}13 \\
14 v . \\
15 v ., 16 \\
21 \\
21 v .\end{array}$ \\
\hline 1 & voloncocob & árbol & Francisco Che, alcalde & $2 \mathrm{v}$. \\
\hline 1 & almehen & noble & Pedro Keh, principal & $10 \mathrm{v}$. \\
\hline 5 & ah kin & sacerdote & $\begin{array}{l}\text { Agustín Dzul } \\
\text { Pedro Pix } \\
\text { Pedro Col } \\
\text { Francisco Pech } \\
\text { Sentencia }\end{array}$ & $\begin{array}{l}15 \mathrm{v} . \\
16 \mathrm{v} . \\
17 \mathrm{v} . \\
19 \\
25 \mathrm{v} .\end{array}$ \\
\hline 1 & ah kulel & munidor & Agustín Dzul & $15 \mathrm{v}$. \\
\hline 3 & $\begin{array}{l}\text { ah patom } \\
\text { patom }\end{array}$ & ollero & $\begin{array}{l}\text { Ana Quime } \\
\text { Catalina Dzul }\end{array}$ & \begin{tabular}{|l}
6 \\
7 (2 vcs)
\end{tabular} \\
\hline 1 & kakalche & milpa & Juan Tec & 15 \\
\hline 1 & kakche & milpa & Pedro Col & 18 \\
\hline 2 & kanleox & idolo & $\begin{array}{l}\text { Juan Tec } \\
\text { Juan Na }\end{array}$ & \begin{tabular}{|l}
15 \\
$18 \mathrm{v}$.
\end{tabular} \\
\hline 1 & tabay & ídolo & Pedro Pix & $16 \mathrm{v}$. \\
\hline 1 & ah chac & ídolo & Pedro Pix & $16 \mathrm{v}$. \\
\hline 4 & kin popol tun & ídolo & $\begin{array}{l}\text { Juan Tun } \\
\text { Juan Tec } \\
\text { Pedro Col } \\
\text { Sentencia }\end{array}$ & $\begin{array}{l}13 v . \\
14 v . \\
17 v . \\
26\end{array}$ \\
\hline 5 & kin colop u uich kin & ídolo & $\begin{array}{l}\text { Juan Tun } \\
\text { Juan Tec } \\
\text { Pedro Col } \\
\text { Francisco Pech } \\
\text { Sentencia }\end{array}$ & $\begin{array}{l}13 v . \\
14 v . \\
17 v . \\
20 \\
26\end{array}$ \\
\hline 4 & kin dzapah tum & ídolo & $\begin{array}{l}\text { Juan Tun } \\
\text { Pedro Col } \\
\text { Francisco Pech } \\
\text { Sentencia }\end{array}$ & $\begin{array}{l}13 v . \\
17 v \\
20 \\
26\end{array}$ \\
\hline 4 & ix ahau caan & ídolo & $\begin{array}{l}\text { Juan Tun } \\
\text { Pedro Col } \\
\text { Francisco Pech } \\
\text { Sentencia }\end{array}$ & $\begin{array}{l}13 \\
17 v \\
20 \\
26 \\
\end{array}$ \\
\hline 1 & kin chachau itzamna & ídolo & Francisco Pech & 20 \\
\hline
\end{tabular}

FIG. 1 - Presencia de vocablos mayas en el proceso de Peto. 


\begin{tabular}{|l|l|l|l|}
\hline \multicolumn{1}{|c|}{$\mathbf{N}^{\mathbf{0}}$ réplicas } & \multicolumn{1}{|c|}{ Discurso atribuido a } & Testigo que reporta el discurso & \multicolumn{1}{|c|}{ Folios } \\
\hline 1 & Francisco Pech & Melchior Xiu & 2 \\
\hline 4 & $\begin{array}{l}\text { Francisco Pech } \\
\text { Francisco Che }\end{array}$ & Francisco Che & 3 \\
\hline 1 & $\begin{array}{l}\text { Inés Dzul } \\
\text { Anan Tun }\end{array}$ & Gaspar Col & 5 \\
\hline 2 & $\begin{array}{l}\text { Juan Tun } \\
\text { Ana Dzuma, su mujer }\end{array}$ & Catalina Dzul & 7 \\
\hline 4 & Francisco Pech & Juan Tun (confesión) & 8 \\
\hline 2 & Francisco Pech & Juan Tec (confesión) & $12 \mathrm{v} ., 13 \mathrm{v}$. \\
\hline 2 & Francisco Pech & Pedro Col (confesión) & $17 \mathrm{v}$. \\
\hline 3 & Francisco Pech & Juan Na (confesión) & $18 \mathrm{v} ., 19$ \\
\hline 3 & & & \\
\hline
\end{tabular}

FIg. 2 - Presencia del discurso directo en el proceso de Peto.

\begin{tabular}{|l|l|l|l|l|}
\hline \multicolumn{1}{|c|}{$\mathbf{N}^{\mathbf{0}}$} & \multicolumn{1}{c|}{ Propietario } & \multicolumn{1}{c|}{ Lugar } & \multicolumn{1}{c|}{ Ídolo } & \multicolumn{1}{c|}{ Ofrendas } \\
\hline 1 & Francisco Pech & Milpa, en un cedro & Ix Ahau Caan & copal y hojas verdes \\
\hline 1 & Gaspar Pix & Milpa kakalche & Kanleox & copal \\
\hline 2 & Agustín Dzul & $?$ & $?$ & copal y una cuzca \\
\hline 2 & Pedro Pix & $?$ & Tabay y Ah Chac & sacrificios \\
\hline 1 & Juan Tec & Milpa kakche & $?$ & $?$ \\
\hline 1 & Juan Na & Cueva & Kanleox & pan, poçol y copal \\
\hline
\end{tabular}

FIG. 3 - Información sobre los ídolos en el proceso de Peto ${ }^{71}$.

\section{NoTAS}

Agradezco a los especialistas de la revista por sus enriquecedores comentarios que me abrieron nuevas perspectivas tanto a nivel de contenidos, como de metodología y que, por tanto, contribuyeron a mejorar la versión original de este trabajo. También agradezco a la doctora Manuela Cristina García Bernal y al doctor Michel Boccara por la revisión que hicieron de este artículo y por sus consejos. No obstante, los posibles errores de interpretación son responsabilidad mia.

1. La cuestión, que sintetizamos aquí, es compleja, ya que algunos religiosos parecen haber aceptado de manera consciente cierto grado de sincretismo con el objetivo de facilitar la adopción del catolicismo por parte de los indios.

2. Varios juicios de idolatría hechos en el centro de México entre 1536-1547 fueron publicados en González Obregón (2002). En Yucatán, los procesos de 1562 revelan, con un desfase de dos décadas que se explica por las fechas distintas de las conquistas de las dos áreas, los mismos problemas religiosos (Scholes y Adams 1938; Clendinnen 1986).

3. Sobre el papel de la religión en las rebeliones mayas, consúltense Bricker (1989), Solís Robleda y Peniche Moreno (1996) y Kosner (1998). Para un estudio del sincretismo en la zona maya, véase Farriss (1992, pp. 453-488).

4. Probanza de méritos del clérigo Baltasar de Herrera, 1598-1599 (Archivo General de Indias o AGI, México, 292, 28 folios). Cabe señalar que Chuchiak (2000, pp. 1-19; 2001, pp. 155-158; 2002, 
pp. 141-143, 155-159) y Caso Barrera (1999) han comentado el proceso de idolatría contenido en la probanza en algunos trabajos.

5. Ambrosio de Arguelles, escribano público, sacó una copia de los originales del proceso y la agregó a la probanza en julio de 1599 (Certificación del escribano público, 17 de julio de 1599, en la probanza de Baltasar de Herrera, 1598, folios 27v-28).

6. Nombramiento de Francisco Sánchez de Urbina, notario, 14 de marzo de 1598 (en la probanza de Baltasar de Herrera, 1598, folio 1).

7. Testimonio de Francisco Che, alcalde de Calatamul (en la probanza de Baltasar de Herrera, 1598 , folios $2 \mathrm{v} \cdot-3)$.

8. Los mayas inculpados fueron Juan Na, Juan Tec, Pedro Pix, Gaspar Che y su hijo Pedro Col, Agustín Dzul, alguacil, Juan Tun y Andrés Chim (Testimonios de Gaspar Col, Melchior Dzul y Ana Quime, en la probanza de Baltasar de Herrera, 1598, folios 4-6).

9. Auto de remisión a su señoría, 16 de mayo de 1598 (en la probanza de Baltasar de Herrera, 1598, folio 9).

10. Comisión de su señoría al vicario de Peto para conocer las idolatrias, 1 de junio de 1598 (en la probanza de Baltasar de Herrera, 1598, folio 9).

11. MacLeod (1998) dedicó un artículo al análisis del contexto de creación de las probanzas y de los objetivos perseguidos por los promotores de estos documentos.

12. Un ejemplo de beneficio dividido a raíz de un proceso de idolatría está tratado en Izquierdo (1988).

13. Cabe señalar que el empleo de mayas en tareas supuestamente reservadas a españoles no se limitó a la lucha en contra de la idolatría, sino que también se dio en la evangelización, con la creación de cargos de maestros de escuela indigenas (Cunill 2008).

14. Testimonio de don Diego Chan (en la probanza de méritos del padre Antonio de Arroyo, clérigo presbítero beneficiado del partido de Peto, 1604, AGI, México, 294).

15. Testimonio de don Diego Baz (en la probanza de méritos del padre Antonio de Arroyo, 1604).

16. Lockhart (1999) se puede considerar como el padre de la nueva filología que Restall (1997) y Okoshi Harada (1992) emplearon en sus trabajos sobre los mayas de la Colonia. Una apasionante reconstrucción de la historia de la nueva filología aparece en Restall (2003). Monod Becquelin y Erikson (2000) y Hanks (1990) también han puesto de manifiesto el interés de la lingüística para el estudio etnológico. Para la región andina colonial, cabe señalar los estudios etnolingüísticos de Itier (1992; 2004) sobre el material ritual contenido en los juicios de idolatría de la zona.

17. Para el nahuatl, Lockhart (1999); para el maya, Restall (1997, pp. 292-303) y Hanks (1986).

18. En el campo de la lingüística histórica, algunos estudios se han centrado en el papel del sustrato indígena en la conformación del español americano mediante el análisis de la presencia de indigenismos en escritos del siglo XVI, especialmente en las crónicas (Bastardín Candón 2001).

19. Los hijos de españoles nacidos en la penísula solian aprender el maya desde su más tierna edad con sus nodrizas, llamadas indias chichiguas, y lo seguían practicando con los indigenas que servian en sus casas (García Bernal 1977, pp. 14-16).

20. No tomamos en cuenta el mayismo cenote, del maya dzonot, dado que la palabra entró rápidamente en el castellano hablado en la península, siendo la principal razón de esta temprana adopción la peculiaridad de aquel fenómeno natural.

21. El copal, del nahuatl copalli, es un tipo de incienso, el pochote un árbol y el pozol o pozole una bebida tradicional elaborada con maíz y azúcar. Las tres voces van repertoriadas en el Diccionario de la Real Academia española (o $D R A E$ ) y siguen en uso hoy en día en América. No obstante, es de notar que en el juicio de idolatría que nos ocupa el término pozol, también ortografiado bajo la forma poçol, designaba una bebida de cacao que tal vez también contenía maíz, pese a que ningún testigo juzgara necesario precisarlo. Agradezco a uno de los lectores de la revista por llamar mi atención sobre esta importante diferencia.

22. Sería interesante saber en qué medida la conquista española pudo contribuir a intensificar el proceso de adopción de nahuatlismos en el idioma maya. 
23. Zuhuy lac, de zuhuy, virgen y lac, "plato o cajete en el que comen los indios y tómase por cualquier plato o escudilla, idem llaman así los idólatras a los idolos que hacen de barro " (Arzápalo Marín 1995, I, p. 442). Copo, « árbol conocido en esta tierra, especie de higuera y lleva unos higos pequeños " (ibid., p. 136).

24. La figura 1 (ver apéndices) sinteza las referencias de los vocablos mayas a lo largo del proceso de 1598 .

25. El DRAE registra jicara, " del nahua xicalli, vaso hecho de la corteza del fruto de la güira, vasija pequeña de madera, ordinariamente hecha de la corteza del fruto de la güira, $\mathrm{y}$ usada como la de loza del mismo nombre en España ». El equivalente maya de jicara es luch (Arzápalo Marín 1995, I, p. 471).

26. Su equivalente maya podría ser $\mathrm{kan}$, « cuescos o piedras que servían a los indios de moneda y de adorno al cuello ", o tum, "piedra preciosa, nombre genérico " (Arzápalo Marín 1995, I, pp. 408,731 ).

27. La figura 2 (ver apéndices) contiene el número de réplicas tanto del locutor original, como del testigo que las enunció.

28. Pensamos, por ejemplo, en los trabajos de Baudez (2002), Boccara (1990; 2002), Hanks (1993), Monod Becquelin y Erikson (2000), Monod Becquelin y Vapnarski (2005).

29. Confesiones de Juan Tec y Juan Na (en la probanza de Baltasar de Herrera, 1598, folios 1518v.; Garza 1998, p. 111). De kan, « maíz », y ox, « capullo de algodón cerrado o abierto » (Arzápalo Marín 1995, I, pp. 409, 602).

30. Confesión de Pedro Pix (en la probanza de Baltasar de Herrera, 1598, folio 16v.). En el Calepino, el término tab se traduce como « atadero, cuerda, ramal con que se ata algo y del que cuelga alguna cosa " y taabal, " ser atado o atarse; ligarse, o ser ligado el pájaro en la liga, caer en el lazo, ser asido en él » (Arzápalo Marín 1995, I, pp. 675-676). Según de la Garza (1998, pp. 121-122), Tabay y Zib eran protectores de los venados y Tabay era " diosa de la naturaleza salvaje en general ». En el Ritual de los Bacabes, se menciona dos veces a Ah Tabay, El-de-la cuerda (Arzápalo Marin 2007, pp. 76, 99). A pesar de que, en términos coloniales, se hablaba de Tabay como dios o diablo, actualmente es una figura de tipo maestro de los animales (comunicación de uno de los lectores anónimos del Journal de la Société des Américanistes).

31. Según Juan Uc, el dios de la caza se llamaba Aquehe. Sin duda, aquel nombre corresponde a Ah Queh, ya que keh significa " venado » en maya (Scholes y Adams, 1938, I, p. 62).

32. Hoy en día en Yucatán, se sigue celebrando la ceremonia del cha'a chak para que llegue la lluvia en las milpas de los agricultores mayas.

33. La figura 3 (ver apéndices) sintetiza la información sobre los ídolos contenida en el proceso de 1598 .

34. Confesión de Pedro Col (en la probanza de Baltasar de Herrera, 1598, folio 17).

35. Sobre el progresivo cambio en la repartición de los ídolos entre los mayas, véase Chuchiak (2009). El autor demuestra cómo en el siglo xvi el $40 \%$ de los ídolos se encontraba en casas, el $5 \%$ en los montes, el $20 \%$ en cuevas y cenotes, el $15 \%$ en ruinas y el $5 \%$ en las costas, mientras que en el siglo Xvir sólo el $15 \%$ se localizaba en los pueblos, el $30 \%$ en las milpas, el $20 \%$ en los montes, el $20 \%$ en cuevas, el $10 \%$ en ruinas y el $5 \%$ en el mar.

36. Testimonio de Francisco Che (en la probanza de Baltasar de Herrera, 1598, folio 3).

37. Confesiones de Melchior Xiu y de Francisco Che, respectivamente (en la probanza de Baltasar de Herrera, 1598, folio 3).

38. Tal vez se pueda poner en relación el uso ritual de las piedras cuzcas con la importación de abalorios provenientes de Sevilla, de forma que es posible, aunque no deja de ser irónico, que los mayas adquirieran de los mismos españoles los productos que necesitaban para sus ceremonias idolátricas (García Bernal 2000, p. 226).

39. Testimonio de Francisco Che (en la probanza de Baltasar de Herrera, 1598, folios 2v.-3). Más conocido que el bolonkokob es la hoja del árbol sagrado llamado habin que se colocaba sobre los altares donde los mayas depositaban a sus dioses (Chuchiak 2001, p. 145; Garza 1998, p. 59). 
40. Confesiones de Juan Tec, Juan Tun y Ana Quime (en la probanza de Baltasar de Herrera, 1598, folios 13, 14v., 21).

41. El "colgadero en que traen o llevan las jicaras de chocolate » se llamaba chuyubil luch (Arzápalo Marín 1995, I, pp. 269-270). Según Chuchiak (2001, p. 136), el balché también se vertía dentro de nueve o trece jicaras, número simbólico que tenía que ver con las trece capas del cielo y las nueve del inframundo. Hanks (1990, p. 346) explica que, en determinadas ceremonias actuales, los mayas siguen repartiendo bebidas en cuatro jicaras colocadas en el altar.

42. Testimonio de Gaspar Col (en la probanza de Baltasar de Herrera, 1598, folios 4-5). Según Chuchiak (2003, pp. 36-37), en los rituales de balché los mayas seguían los mismos procedimientos. Sobre el uso actual del balché, véase Gabriel (2007). Por otra parte, al parecer, los mayas utilizaban bebidas distintas según el rito celebrado. Chuchiak (2001, pp. 145-146) señala, por ejemplo, que durante el mes Uo los sacerdotes bendecían los libros sagrados con agua virgen llamada zuhuy ha.

43. Para más información sobre los ah kines, sus funciones, ornamentos y asistentes, ver Chuchiak (2001, pp. 135-160).

44. Testimonio de Pedro Keh (en la probanza de Baltasar de Herrera, 1598, folio 10v.).

45. Sentencia (en la probanza de Baltasar de Herrera, 1598, folio 25v.). Según Covarrubias (1995, p. 459), embair significa " engañar persuadiendo con mentiras, con razones y cosas aparentes " o " instituir, enseñar, porque el maestro hinche el entendimiento y la memoria de la doctrina y el embaidor de falsos conceptos, haciéndole creer lo que no es ").

46. Confesión de Agustín Dzul (en la probanza de Baltasar de Herrera, 1598, folio 16).

47. En la entrada $k u l$ se encuentra una definción más completa de la función civil del $a h k u l e l$, « ah kulel u kul batab: indio a quien el cacique manda cosas de gobierno del pueblo y de quien anda siempre acompañado » (Arzápalo Marín 1995, I, pp. 30, 436).

48. En el Calepino, ah patcum se traduce como ollero, mientras que ah pat es « el que hace cosas de barro o cera " (Arzápalo Marín 1995, I, p. 39; testimonios de Ana Quime y de Catalina Dzul, en la probanza de Baltasar de Herrera, 1598, folios 6-6v.).

49. Comisión para conocer idolatrias dada a Antonio de Arroyo el 8 de abril de 1603 (en la probanza de Antonio de Arroyo, 1604).

50. Sentencia (en la probanza de Baltasar de Herrera, 1598, folio 26v.).

51. Confesión de Agustín Dzul (en la probanza de Baltasar de Herrera, 1598, folio 16. Los itálicos son míos).

52. En los últimos años han surgido trabajos sobre el papel de la mujer en la sociedad colonial. El número 4 del volúmen 42 de la revista Ethmohistory del año 1995 está enteramente dedicado al tema de la mujer en Mesoamérica (véanse también Clendinnen 1982b; Restall 1995; Wood 1998; Sigal 2000).

53. Confesión de Ana Quime (en la probanza de Baltasar de Herrera, 1598, folio 21).

54. Chuchiak (2003, pp. 38-41) revela que, en 1640, varias mujeres mayas participaron en rituales con balché en el pueblo de Tibac.

55. Testimonio de Juan Tun (en la probanza de Baltasar de Herrera, 1598, folios 7v.-8).

56. Existe confusión en cuanto al nombre de la nuera de Francisco Pech, dado que Gaspar Col la llamó Inés Dzul, y que Melchior Dzul la llamó Catalina Dzul. Nos inclinamos a pensar que se llamaba Catalina, porque su madre, Ana Quime, la llamó así.

57. Testimonio de Gaspar Col (en la probanza de Baltasar de Herrera, 1598, folios 4-5).

58. Confesión de Agustín Dzul (en la probanza de Baltasar de Herrera, 1598, folios 15-16).

59. Sobre un estudio del papel de la religión en la organización sociopolítica maya durante la Colonia, ver Solís Robleda (2005). Sobre la dimensión política de las prácticas religiosas nahuas y zapotecas en los siglos XVı y XVII, ver Távarez (2002).

60. Testimonio de Francisco Che (en la probanza de Baltasar de Herrera, 1598, folios 2v.-3).

61. Confesión de Pedro Col (en la probanza de Baltasar de Herrera, 1598, folios 18-18v.).

62. Confesión de Juan Na (en la probanza de Baltasar de Herrera, 1598, folios 19-19v.).

63. Testimonio de Catalina Dzul (en la probanza de Baltasar de Herrera, 1598, folio 7).

64. Confesión de Juan Tun (en la probanza de Baltasar de Herrera, 1598, folios 12-13v.). 
65. Confesión de Juan Na (en la probanza de Baltasar de Herrera, 1598, folio 19).

66. Testimonio de Catalina Dzul (en la probanza de Baltasar de Herrera, 1598, folios 6v.-7v.).

67. Confesión de Pedro Quime (en la probanza de Baltasar de Herrera, 1598, folios 21-21v.). Pedro Quime fue condenado a « 24 azotes y a que oiga una misa con soga y vela en la mano y en las costas ", es decir a la mitad de la condena infligida a los demás idólatras (Sentencias, en la probanza de Baltasar de Herrera, 1598, folios 26v.-27).

68. El equivalente inglés de resurgimiento es revival (véase Jones 1990). Sobre el papel de la memoria en el mantenimiento de las tradiciones y de los procesos identitarios actuales, ver Monod Becquelin y Molinié (1993).

69. Otros gobernadores, como don Juan Chan, participaron aún más activamente en la extirpación de la idolatria, puesto que buscaron indios idólatras fuera de la esfera de sus propios pueblos (Bracamonte y Sosa 2001, pp. 173-182; Quezada 1989).

70. En el proceso de 1598 sólo uno de los sentenciados, Agustín Dzul, era alguacil (testimonio de Gaspar Col, en la probanza de Baltasar de Herrera, 1598, folio 4v.). Sobre la implicación de los caciques y gobernadores mayas yucatecos en las redes de intercambios del balché y su participación en rituales donde se consumía esta bebida, ver Chuchiak (2003, p. 42).

71. Pedro Col afirmó que Agustín Dzul y Juan Tec tenían tres ídolos: Kin Dzapah Tun, Kin Popol Tun y Kin Colop U Uich Kin, pero no precisó la repartición de estos ídolos entre ambos mayas, por lo que no se ha podido completar parte del cuadro.

\section{REFERENCIAS CITADAS}

Arzápalo Marín Ramón (ed.)

1995 Calepino de Motul, UNAM, México.

2007 El ritual de los Bacabes, UNAM, México.

BASTARDín CANDÓN Teresa

2001 "Vitalidad de los términos indigenas en la Historia de las cosas de Nueva España de fray Bernardino de Sahagún », memoria de licenciatura, Universidad de Cádiz, Cádiz [en línea].

BAudez Claude-François

2002 Une histoire de la religion des Mayas. Du panthéisme au panthéon, Michel Albin, Paris.

BoCCARA Michel

1990 Entre métamorphose et sacrifice. La religion populaire des Mayas, L'Harmattan, Paris.

2002 La part animale de l'homme. Esquisse d'une théorie du mythe et du chamanisme, Anthropos, Paris.

\section{Bracamonte y Sosa Pedro}

2001 La conquista inconclusa de Yucatán. Los mayas de la montaña, 1560-1680, CIESAS, coll. «Peninsular », Mérida.

\section{BRICKER Victoria}

1989 El cristo indigena, el rey nativo. El sustrato histórico de la mitología del ritual de los mayas, Fondo de Cultura Económica, México. 
CASO BARRERA Laura

1999 "Religión y resistencia indígena en Yucatán, siglos XVI-XIX », Historia Mexicana, 48 (4), pp. 153-184.

\section{CHUCHIAK John F. IV}

2000 "The Indian inquisition and the extirpation of idolatry: the process of punishment in the ecclesiastical courts of the Provisorato de Indios in Yucatán, 1553-1812 », PhD dissertation, Tulane University, Tulane.

2001 "Pre-conquest $A$ h Kinob in a colonial world: the extirpation of idolatry and the survival of the Maya priesthood in colonial Yucatán, 1563-1697 », Acta mesoamericana, 12, pp. 135-160.

2002 "Toward a regional definition of idolatry: reexamining idolatry trials in the Relaciones de Méritos and their role in defining the concept of "idolatría" in colonial Yucatán, 1570-1780 », Journal of Early Modern History, 6(2), pp. 140-167.

2003 "It is their drinking that hinders them: balché and the use of ritual intoxicants among the colonial Yucatec Maya, 1550-1780 ", Estudios de Cultura Maya, 24, pp. 1-43.

2009 "De description indolorum: an ethnohistorical examination of the production, imagery, and functions of colonial Yucatec Maya idols and effigy censers, 1540-1700 », in Timothy Pugh y Leslie Cecil (eds), Maya worldview at Conquest, University Press of Colorado, Colorado, pp. 226-285.

\section{Clendinnen Inga}

1982a "Reading the inquisitorial record in Yucatan: fact or fantasy? », The Americas, 28 (3), pp. 327-347.

1982b "Yucatec Maya women and the Spanish conquest: role and ritual in historical reconstruction ", Journal of Social History, 15 (3), pp. 427-442.

1984 "Disciplining the Indians: franciscan ideology and missionary violence in sixteenth-century Yucatan ", Past and Present, 94, pp. 24-49.

1986 Ambivalent Conquest. Maya and Spaniards in Yucatán, 1517-1570, Cambridge University Press, Cambridge.

Covarrubias Orozco Sebastián de

1995 Tesoro de la lengua castellana o española, Editorial Castilia, Madrid.

CUNILL Caroline

2008 «La alfabetización de los mayas de Yucatán y sus consecuencias sociales, 1545-1580 ", Estudios de Cultura Maya, 31, pp. 169-198.

Diccionario de la Real Academia Española (o DRAE)

1992 Real Academia Española, Madrid

FARRISS Nancy

1992 La sociedad maya bajo el dominio colonial. La empresa colectiva de supervivencia, Alianza Editorial, Madrid [Primera edición: Princeton University Press, 1984].

1994 "Conquista y cultura: los mayas de Yucatán », in Carmen Bernand (ed.), Descubrimiento, conquista y colonización de América a quinientos años, Fondo de Cultura Económica, México, pp. 208-211. 
Gabriel Marianne

2007 «El uso del acohol, tabaco, cacao e incienso en las ceremonias agrarias de los mayas yucatecos contemporáneos ", Estudios de Cultura Maya, 29, pp. 156-172.

García Bernal Manuela Cristina

1977 "Los servicios personales en Yucatán durante el siglo Xvı », Revista de la Universidad de Yucatán, 110, pp. 7-21.

2000 "El afianzamiento de un precario comercio: los intercambios entre Sevilla y Yucatán (1590-1600) », Historia Mexicana, 50 (2), pp. 198-240.

GARZA Mercedes de la

1998 Rostros de lo sagrado en el mundo maya, PAIDOS/UNAM, México.

GonZÁlez OBregón Luis (ed.)

2002 Procesos de indios idólatras y hechiceros, Publicaciones del Archivo General de la Nación, México.

GREENLEAF Richard

1965 "The Inquisition and the Indians of New Spain: a study in jurisdictional confusion ", Americas, 22, pp. 138-166.

\section{GRUZINSKI Serge}

1988 La colonisation de l'imaginaire. Sociétés indigènes et occidentalisation dans le Mexique espagnol, xVI-XVI siècles, Gallimard, Paris.

Hanks Williams

1986 "Authenticity and ambivalence in the text: a colonial Maya case ", American Ethnologist, 13 (4), pp. 721-744.

1990 Referential practice, language and lived space among the Maya, University of Chicago Press, Chicago.

1993 "Copresence and alterity in Maya ritual practice ", in Miguel León Portilla, Manuel Gutiérrez Estévez, Gary Gossen y Jorge J. Klor de Alva (eds), De palabra y obra en el Nuevo Mundo, Siglo XXI, Madrid, pp. 75-117.

\section{ITIER César}

1992 «La tradición oral quechua antigua en los procesos de idolatría de Cajatambo », Bulletin de l'Institut français d'études andines, 21 (3), pp. 1009-1051.

2004 "Les caciques de Cajatambo et les cultes autochtones au milieu du $\mathrm{XVII}^{\mathrm{e}}$ siècle ", in Bernard Lavallé (ed.), Les autorités indigènes entre deux mondes. Solidarité ethnique et compromission coloniale, Université de la Sorbonne Nouvelle/Centre de recherche sur l'Amérique Espagnole coloniale, Paris, pp. 147-158.

IzQUIERDo Ana Luisa

1988 «Documentos de la dicisión del beneficio de Yaxcabá. El castigo a una idolatría », Estudios de Cultura Maya, 17, pp. 159-195.

JoNES Grant D.

1990 "Prophets and idol speculators: forces of history in the lowland Maya rebellion of 1638 », in Flora S. Clancy y Peter D. Harrison (eds), 
Vision and revision in Maya studies, University of New Press, Alburquerque, pp. 179-194.

KOSNER Kevin

1998 "Religion and rebellion in colonial Chiapas ", in Susan Schroeder (ed.), Native resistance and the pax colonial in New Spain, University of Nebraska Press, Lincoln/London, pp. 47-66.

\section{LOCKHART James}

1999 Los nahuas después de la conquista. Historia social y cultural de la población indigena del México central, siglos XVI-xviII, Fondo de Cultura Económica, México.

\section{MACLEOD Murdo}

1998 "Self-promotion: the Relaciones de Méritos y Servicios and their historical and political interpretations ", Colonial Latin American Historical Review, 76 (1), pp. 25-42.

Monod BecQuelin Aurore y Antoinette Molinié (eds)

1993 Mémoire de la tradition, Société d'ethnologie, Nanterre.

Monod Becquelin Aurore y Philippe Erikson (eds)

2000 Les rituels du dialogue. Promenades ethnolinguistiques en terres amérindiennes, Société d'ethnologie, Nanterre.

Monod BECQUelin Aurore y Valentina VAPNARSKı (eds)

2005 La rose et le Christ: transmission et appropriation de la Chrétienté dans l'aire maya, Ateliers, 29, Laboratoire d'ethnologie et de sociologie comparative, Nanterre.

\section{OKoshi Harada Tsubasa}

1992 Los camules: análisis etnohistórico del códice de Calkini, tesis de doctorado, UNAM, México.

\section{QueZaDa Sergio}

1989 "Don Juan Chan: un cacique yucateco anti-idolátra », Mayab, 5, pp. 41-44.

Restall Mathew

1995 "He wished it in vain: subordination and resistance among Maya women in post-conquest Yucatan ", Ethnohistory, 42 (4), pp. 577-594.

1997 The Maya world. Yucatec culture and society, 1550-1850, Stanford University Press, Stanford.

2003 "A history of the new philology in history ", Latin American Research Review, 38 (1), pp. 113-134.

\section{RICARD Robert}

2001 La conquista espiritual de México, Fondo de Cultura Económica, México [Primera edición en francés: Institut d'ethnologie, París, 1933].

SAHAGÚN fray Bernardino de

2001 Historia General de las Cosas de la Nueva España, Crónicas de América, Madrid [1577]. 
SCHOLES France V. y Eleanor Adams

1938 Don Diego Quijada, alcalde mayor de Yucatan, 1561-1565, Antigua Librería José Porrúa e hijos, México.

Sigal Pete

2000 From goddesses to virgins: the colonization of Yucatecan Maya sexual desire, University of Texas Press, Austin.

SILVERBLATta Irene

1990 Luna, sol y brujas. Género y clases en los Andes prehispánicos y coloniales, Centro Bartolomé de las Casas, Cusco.

Solís Robleda Gabriela

1994 «Religión y sociedad maya al tiempo de la conquista », Boletín de la Universidad Autónoma de Yucatán, 19 (114), pp. 5-22.

2005 Entre el cielo y la tierra. Religión y sociedad en los pueblos mayas del Yucatán colonial, CIESAS, coll. " Peninsular », Mérida.

Solís Robleda Gabriela y Paola Peniche Moreno

1996 Idolatría y sublevación. Documentos para la historia indigena de Yucatán, UADY, Mérida.

TÁvarez David Eduardo

1999 "La idolatría letrada: un análisis comparativo de textos clandestinos rituales y devocionales en comunidades nahuas y zapotecas, 1613-1654 ", Historia Mexicana, 49 (2), pp. 197-251.

2002 «Letras clandestinas, textos tolerados, colaboraciones licitas: la producción textual de los intelectuales nahuas y zapotecas en el siglo XVII ", in Mónica Quijada y Jesús Bustamante (eds), Élites intelectuales y modelos colectivos: mundo ibérico (siglos XVI-XIX), CSIC, Madrid, pp. 58-82.

TeDLock Dennis

1993 "Terror in the archives: Mayan meet Europeans ", American Anthropologist, 95, pp. 139-152.

Wood Stephanie

1998 "Gender and town guardianship in Mesoamerica: directions for future research », Journal de la Société de Américanistes, 84 (2), pp. 243-276. 